\title{
AQUEOUS RARE EARTH ELEMENT PATTERNS AND CONCENTRATION IN CO-PRODUCED BRINES AND INDUSTRIAL PONDS, WYOMING
}

\author{
Charles Nye ${ }^{1}$ Ghanashyam Neupane ${ }^{2}$ Scott Quillinan ${ }^{1}$ \\ Travis McLing ${ }^{2}$ Fred McLaughlin ${ }^{1}$ Davin Bagdonas ${ }^{1}$ \\ ${ }^{1}$ Carbon Management Institute, University of Wyoming \\ ${ }^{2}$ Idaho National Laboratory
}

SCHOOL OF ENERGY RESOURCES 


\section{Outline}

Serious Title

The Parent Project

Isotope Data

General REE Theory

Measuring ng/L (ppt)

Data by Basin \& Field Conclusions

\section{Cheap Novel Title}

The Big Picture

Inspiration

Overlooked?

The Challenge

Found Fingerprints

Explanation 


\section{Project Objectives}

\begin{tabular}{|c|c|c|c|c|c|}
\hline Element & Type & Applications & Element & Type & Applications \\
\hline $\mathrm{Ce}^{1}$ & REE & Oxidizer and catalyst & $\mathbf{M n}^{1}$ & Trace & Steel alloys and production \\
\hline $\mathrm{Co}^{1}$ & Trace & Batteries and alloys & $\mathbf{N d}^{1}$ & REE & Magnets and capacitors \\
\hline Dy ${ }^{1}$ & REE & Magnets and minor alloys additive & $\mathbf{N i}^{\mathbf{1}}$ & Trace & Multi-purpose metal \\
\hline Er & REE & Lasers and steel alloys & $\mathbf{P r}^{1}$ & REE & Radioactive decay heating \\
\hline $\mathbf{E u}^{1}$ & REE & Lighting and NMR & Sc & REE & Catalyst and lighting \\
\hline $\mathbf{G a}^{1}$ & Trace & Photovoltaics and semiconductors & Sm & REE & Magnets and neutron flux control \\
\hline Gd & REE & Neutron flux control and many alloys & $\mathbf{T b}^{1}$ & REE & Magnets and lasers \\
\hline Ho & REE & Magnets and lasers & Th & Trace & Fuel and lighting \\
\hline $\mathbf{I n}^{1}$ & Trace & Photovoltaic film & $\mathbf{T m}$ & REE & Lighting and lasers \\
\hline $\mathbf{L a}^{1}$ & REE & Catalyst and glass additive & $\mathbf{U}$ & Trace & Fuel and ballast \\
\hline $\mathbf{L} \mathbf{i}^{1}$ & Trace & Flux and batteries & $\mathbf{Y}^{\mathbf{1}}$ & REE & Lasers and steel alloys \\
\hline Lu & REE & Medical tracer and glass additive & Yb & REE & Reducing agent and steel alloys \\
\hline
\end{tabular}

${ }^{1}$ DOE identified critical material

National Database - O\&G and Geothermal REEs Refine Measuring Methods

Statistical Screening to predict occurrence Techno-Economic Assessment 


\section{Project Objectives}

\begin{tabular}{|c|c|c|c|c|c|}
\hline Element & Type & Applications & Element & Type & Applications \\
\hline $\mathrm{Ce}^{1}$ & REE & Oxidizer and catalyst & $M n^{1}$ & Trace & Steel alloys and production \\
\hline $\mathrm{Co}^{1}$ & Trace & Batteries and alloys & $\mathbf{N d}^{1}$ & REE & Magnets and capacitors \\
\hline Dy ${ }^{1}$ & REE & Magnets and minor alloys additive & $\mathbf{N i}^{1}$ & Trace & Multi-purpose metal \\
\hline Er & REE & Lasers and steel alloys & $\mathbf{P r}^{1}$ & REE & Radioactive decay heating \\
\hline $\mathbf{E \mathbf { u } ^ { 1 }}$ & REE & Lighting and NMR & Sc & REE & Catalyst and lighting \\
\hline $\mathbf{G a}^{1}$ & Trace & Photovoltaics and semiconductors & Sm & REE & Magnets and neutron flux control \\
\hline Gd & REE & Neutron flux control and many alloys & $\mathbf{T b}^{\mathbf{1}}$ & REE & Magnets and lasers \\
\hline Ho & REE & Magnets and lasers & Th & Trace & Fuel and lighting \\
\hline $\mathbf{I n}^{1}$ & Trace & Photovoltaic film & $\mathbf{T m}$ & REE & Lighting and lasers \\
\hline $\mathbf{L a}^{1}$ & REE & Catalyst and glass additive & $\mathbf{U}$ & Trace & Fuel and ballast \\
\hline $\mathbf{L i}^{1}$ & Trace & Flux and batteries & $\mathbf{Y}^{1}$ & REE & Lasers and steel alloys \\
\hline Lu & REE & Medical tracer and glass additive & Yb & REE & Reducing agent and steel alloys \\
\hline
\end{tabular}

${ }^{1}$ DOE identified critical material

National Database - O\&G and Geothermal REEs

Refine Measuring Methods

Statistical Screening to predict occurrence

Techno-Economic Assessment 


\section{Ongoing REE Work}

$N \approx 150$

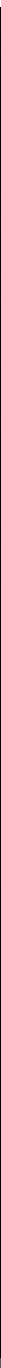

SCHOOL OF ENERGY RESOURCES 


\section{Study Area for this talk}

$N=28$

WRB

2 Fields

PRB

2 Fields

2 Power

Stations

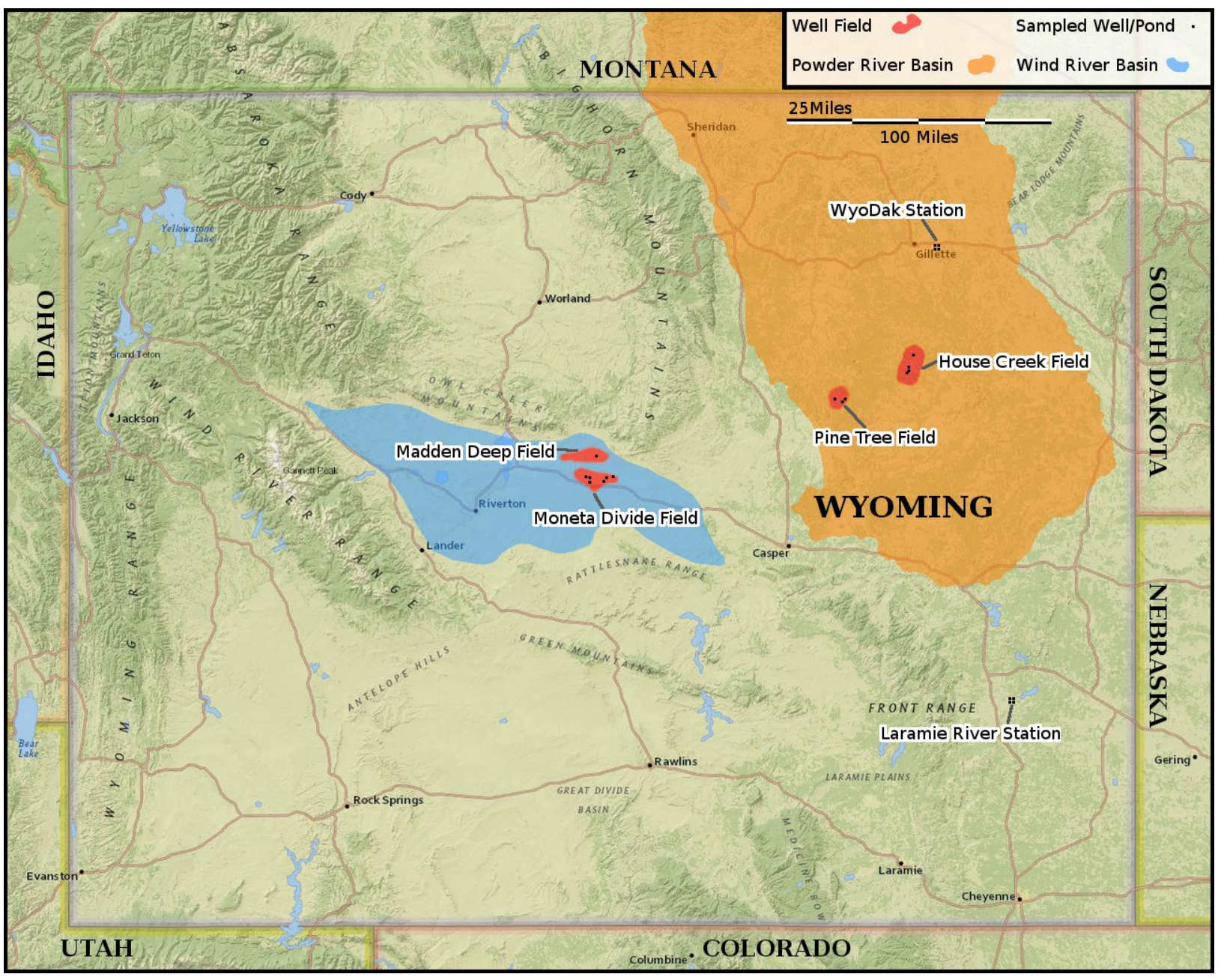

SCHOOL OF ENERGY RESOURCES 


\section{Strata}

WRB:

Young-

Very Old

PRB:

East-

West
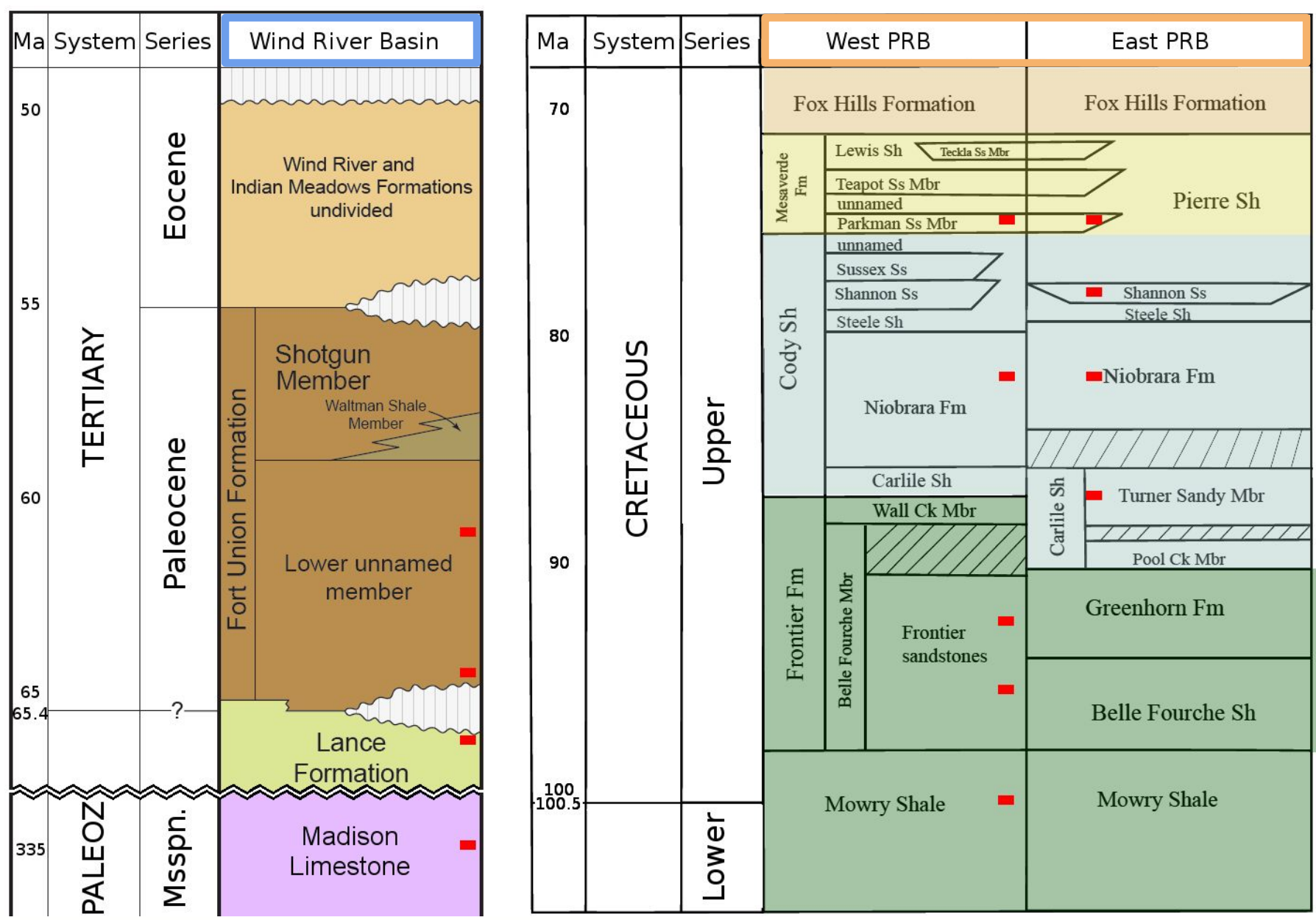


\section{Isotopes: $\delta \mathrm{D}, \delta \mathrm{O}^{18}$}

Right of GMWL

Prolonged Rxn with Rock

Good place to see REEs from rock to water

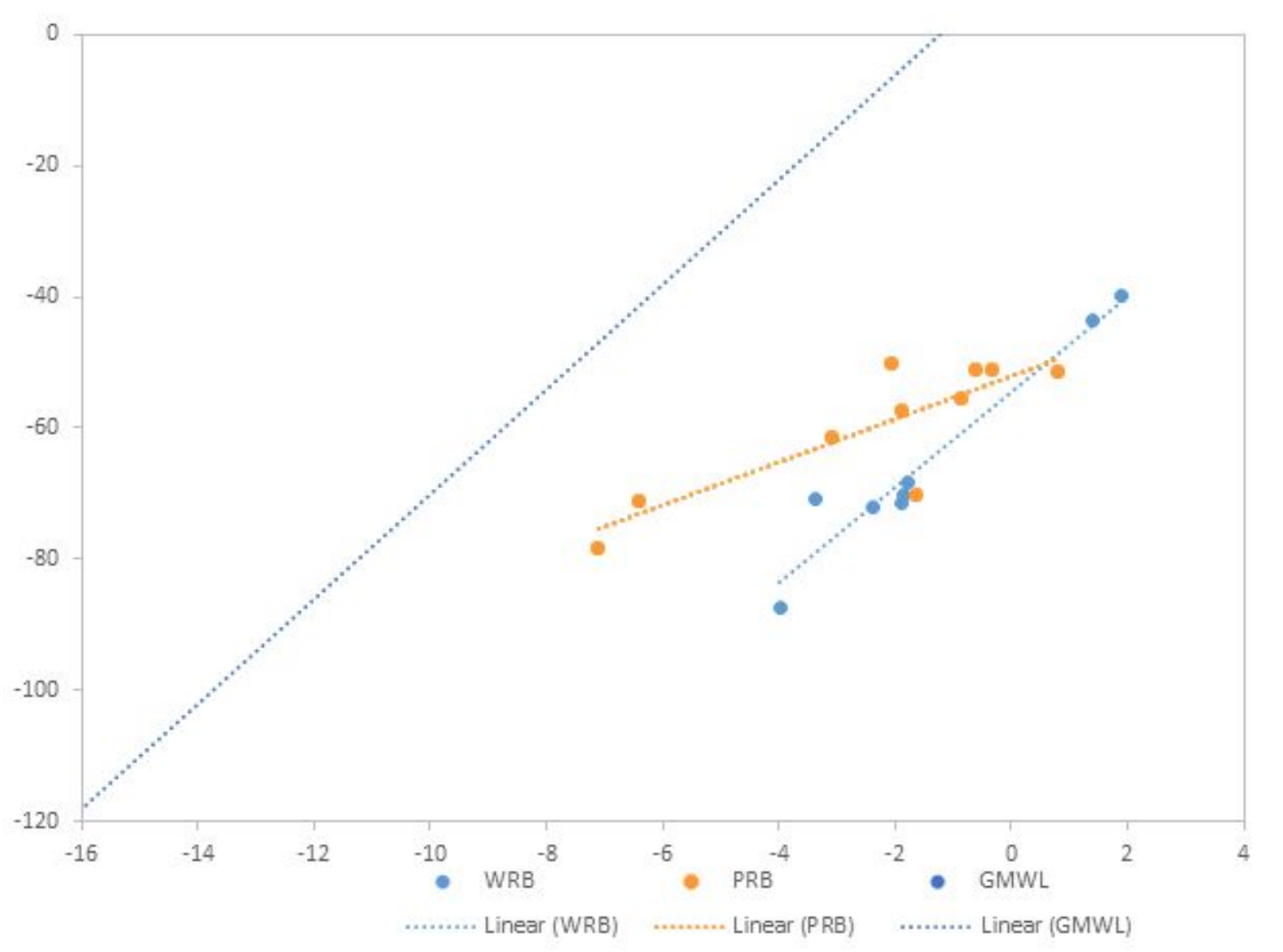




\section{REE Transfer} Mantle

mixing

\section{Emplaced Magma}

fract. crystallization

Igneous Metamorphs

weathering

Loose Sediment

diagenesis

Metasediment
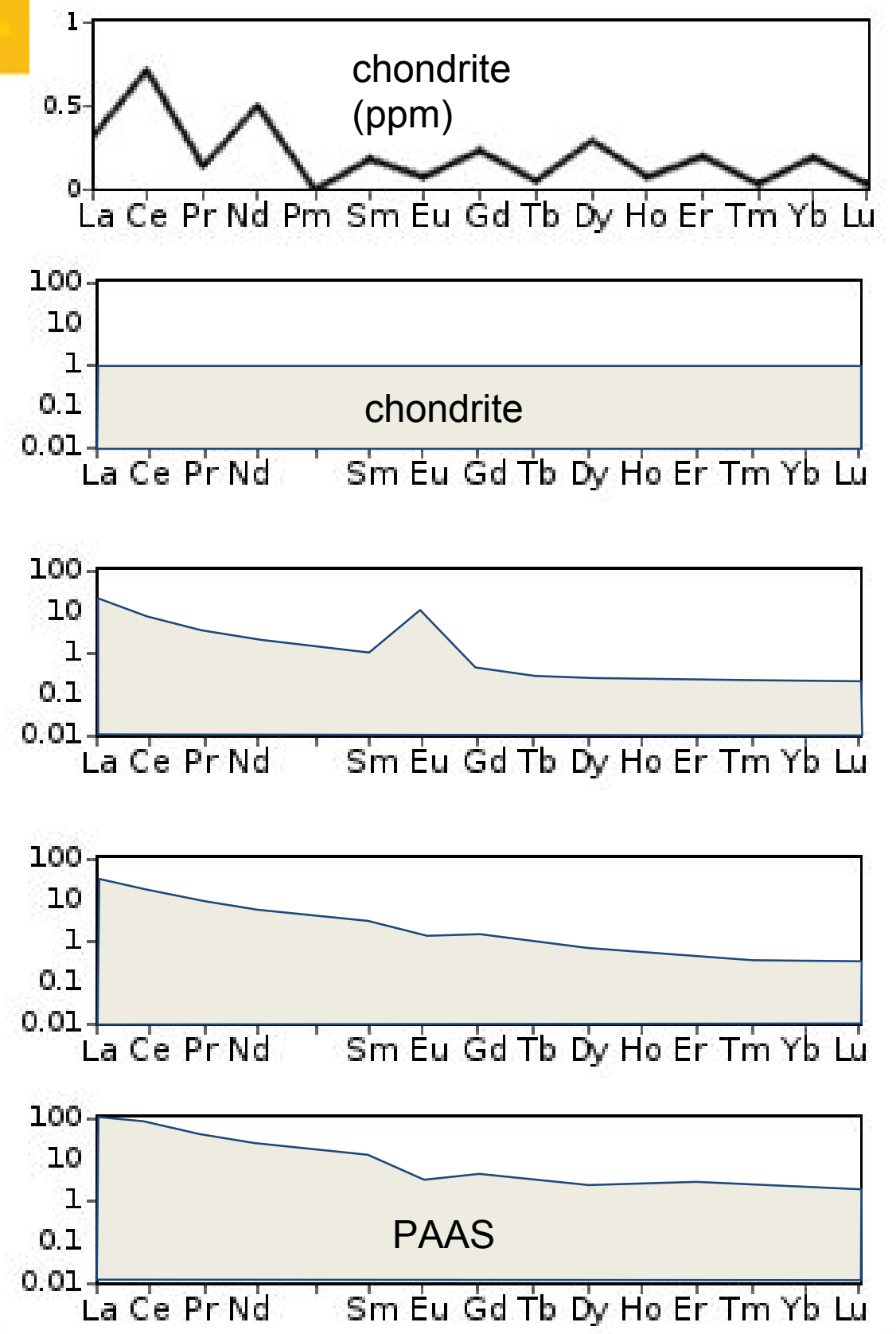


\section{Natural Water REE Transfer Mantle}

mixing

\section{Emplaced Magma}

fract. crystallization Note Ce anomaly

Igneous Metamorphs

weathering

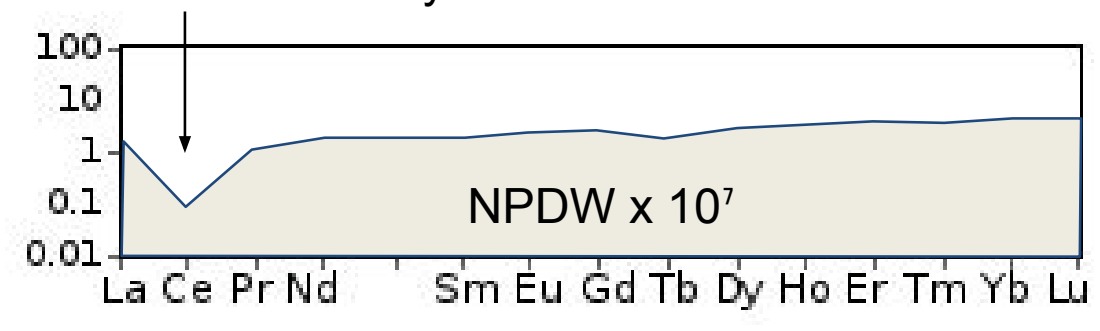

Loose Sediment dissolution Water

diagenesis

Metasediment
Evaporation

Evaporites

SCHOOL OF ENERGY RESOURCES 


\section{Rock normalization inappropriate}

for Water

Solids - Rock, particulate, sediment:

NASC, PAAS, UCC, RSA, GLOSS, and Chondrite

Dissolved $-10^{-7}$ of solids:

NPDW, NADW, AIW, and various rivers.

Deep Basin Brine normalization remains to be developed. 


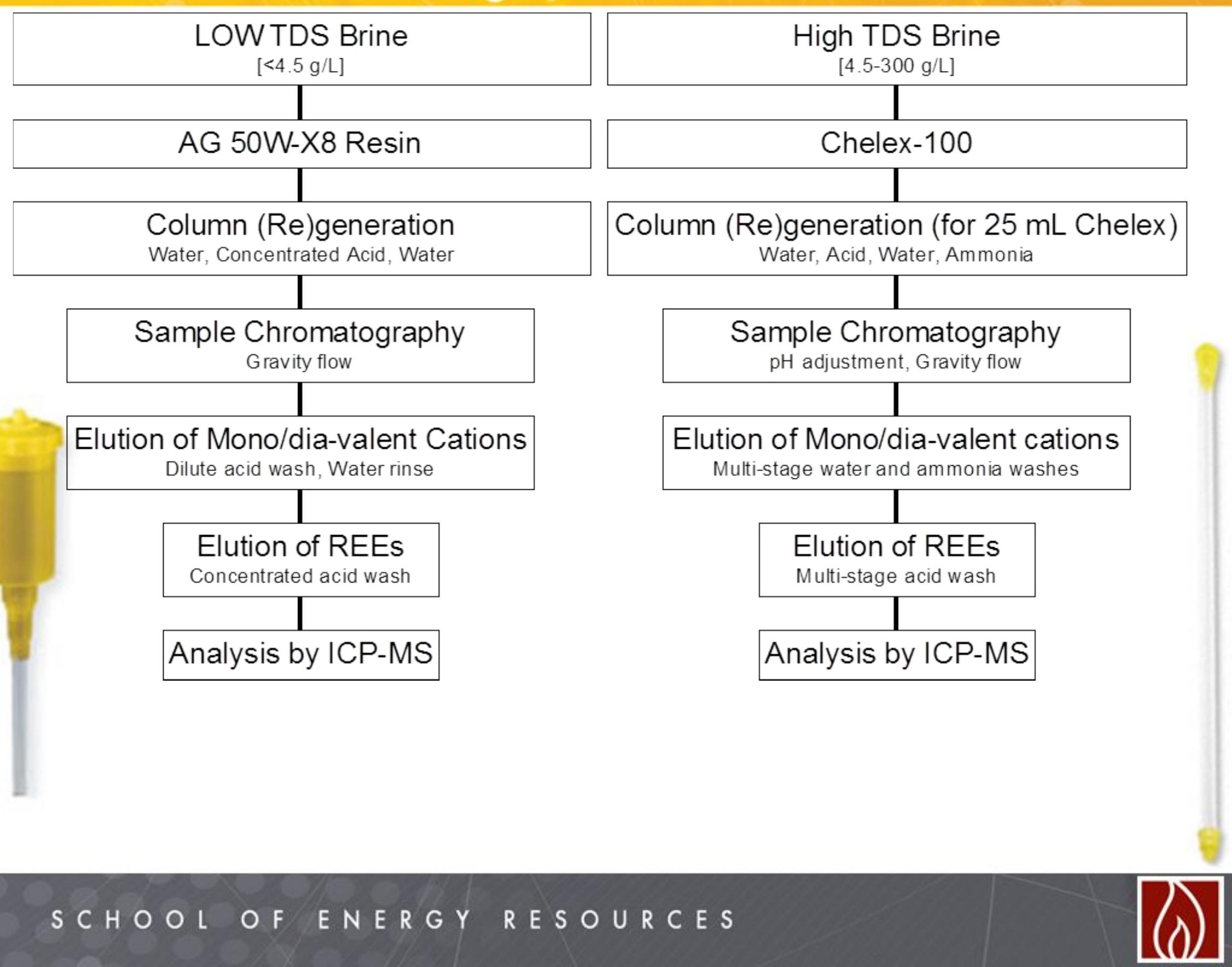




\section{Basin REE}

\section{WRB:}

$\mathrm{Sm} \approx \mathrm{Gd}<<\mathrm{Eu}$
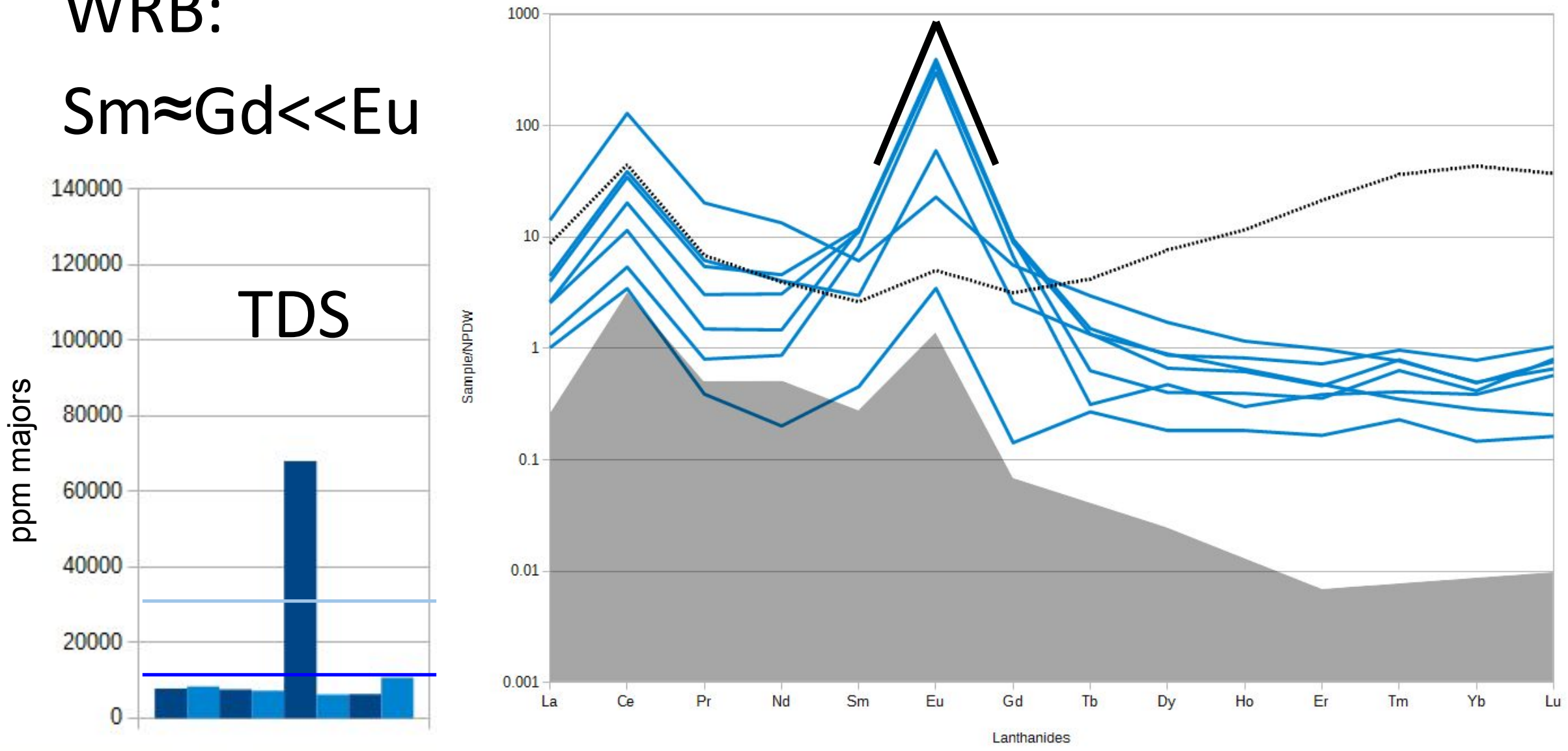

SCHOOL OF ENERGY RESOURCES 


\section{Basin REE}

PRB:

$\mathrm{Sm}<\mathrm{Gd}<\mathrm{Eu}$

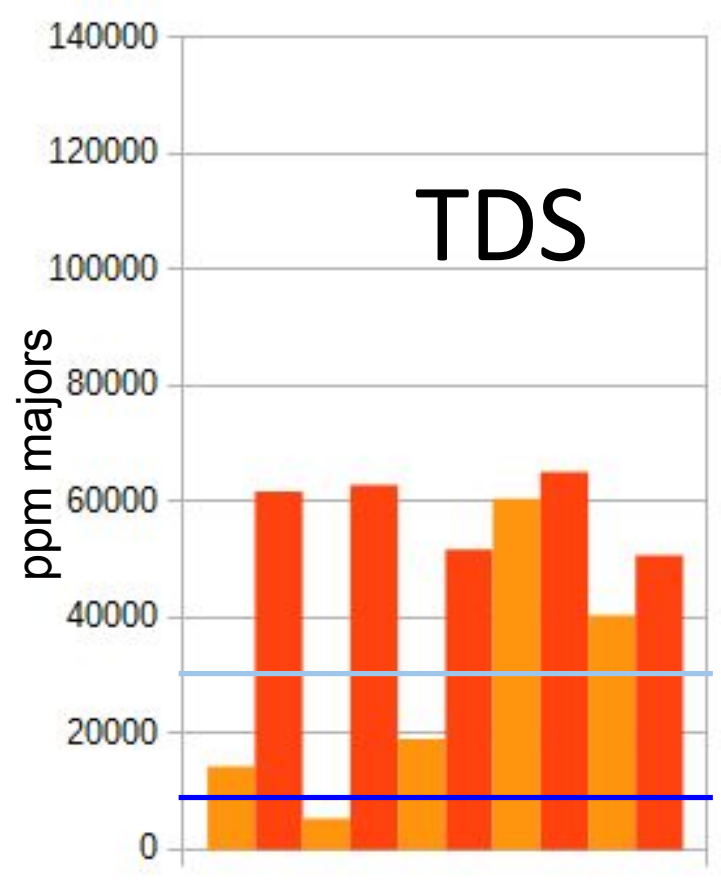

; - House Creek Field

Pine Tree Field

WYOMING

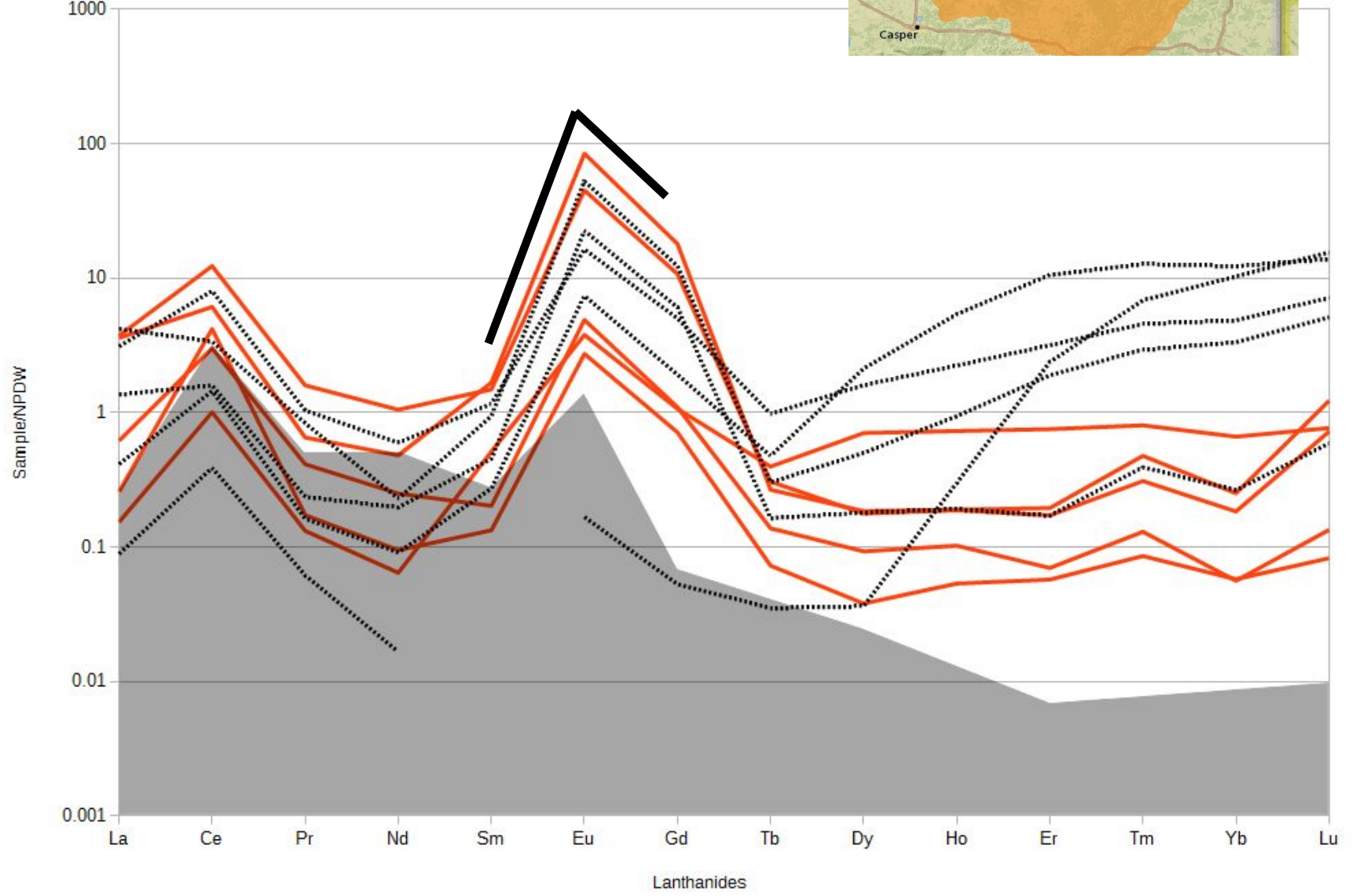

SCHOOL OF ENERGY RESOURCES 


\section{Basin REE}

Industrial:

\section{$\mathrm{Sm} \approx \mathrm{Gd} \approx \mathrm{Eu}$}
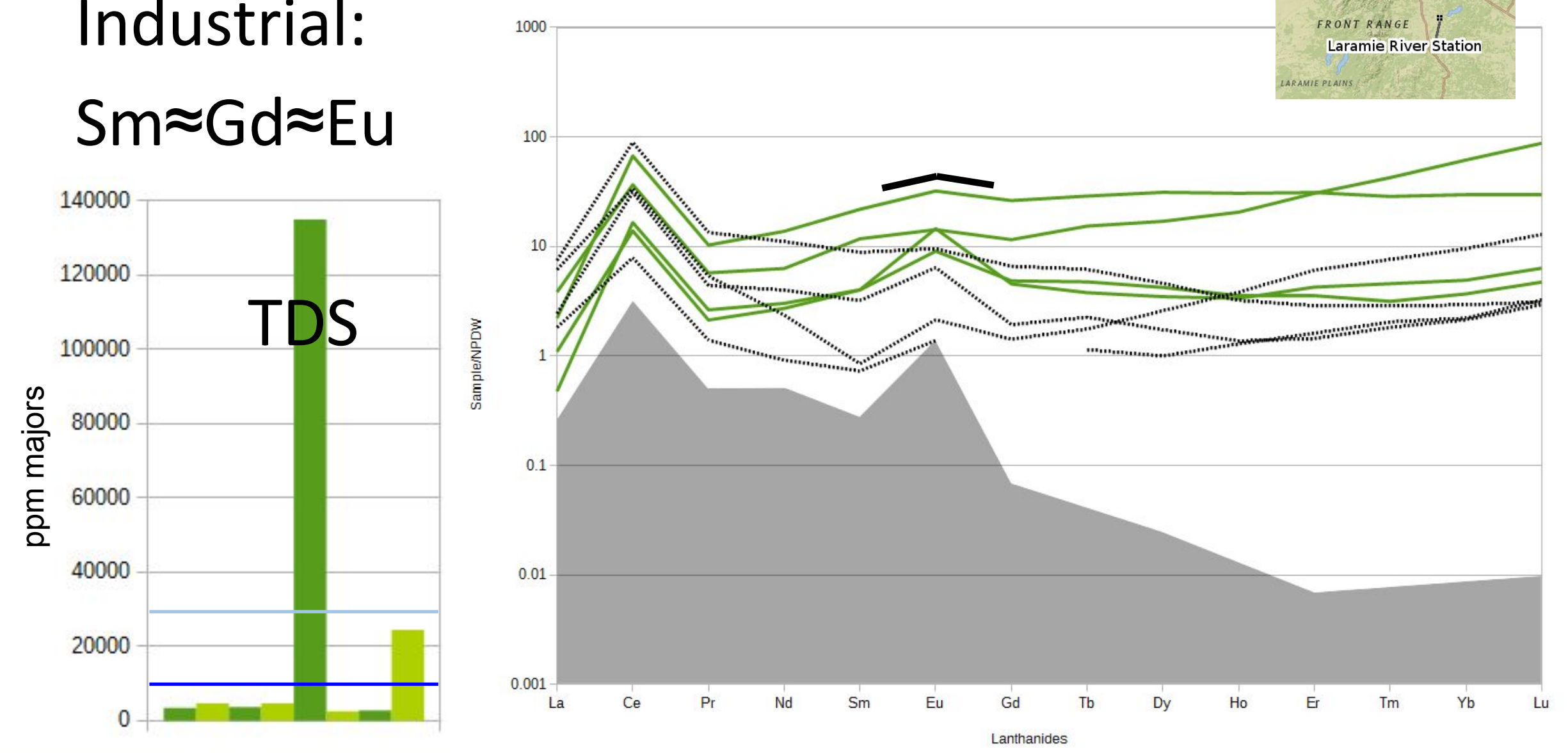

SCHOOL OF ENERGY RESOURCES 


\section{Signature for fields}

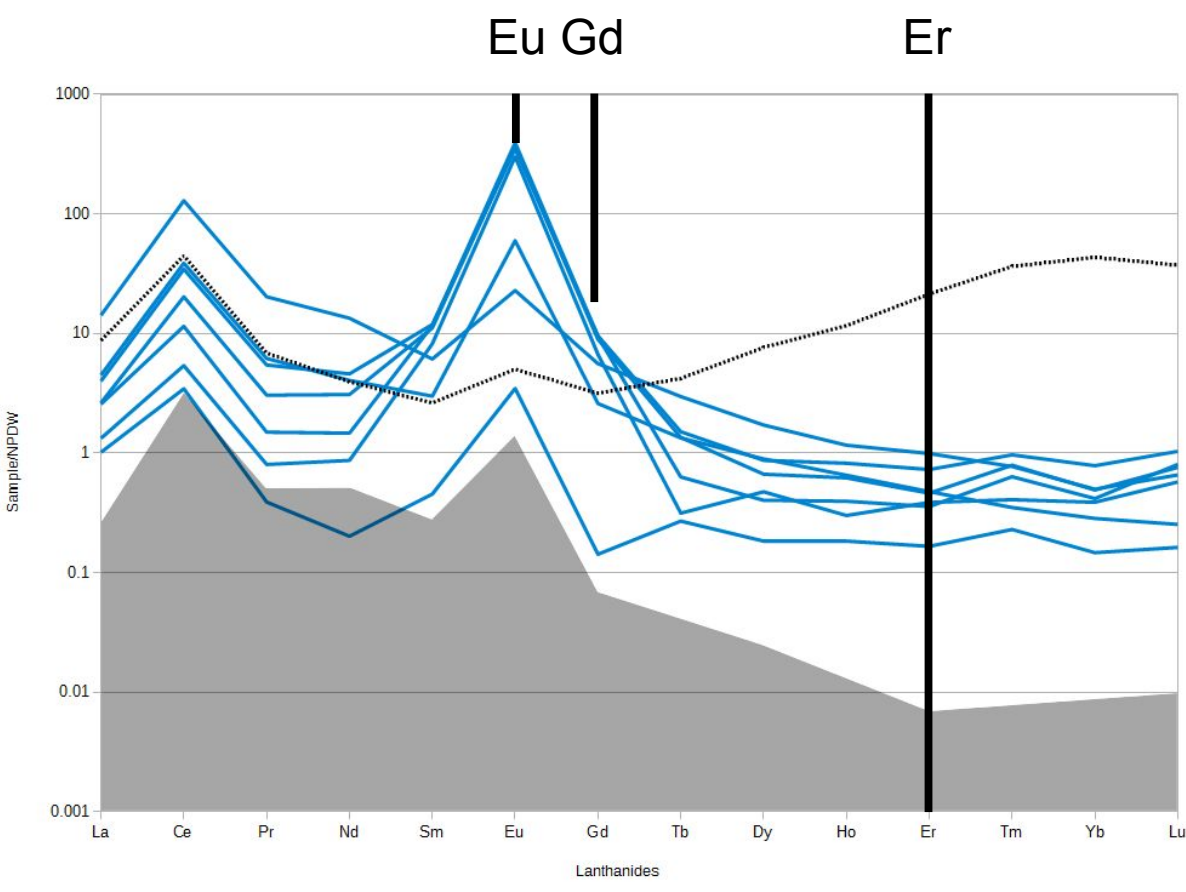

Lost Cabin

Moneta Divide

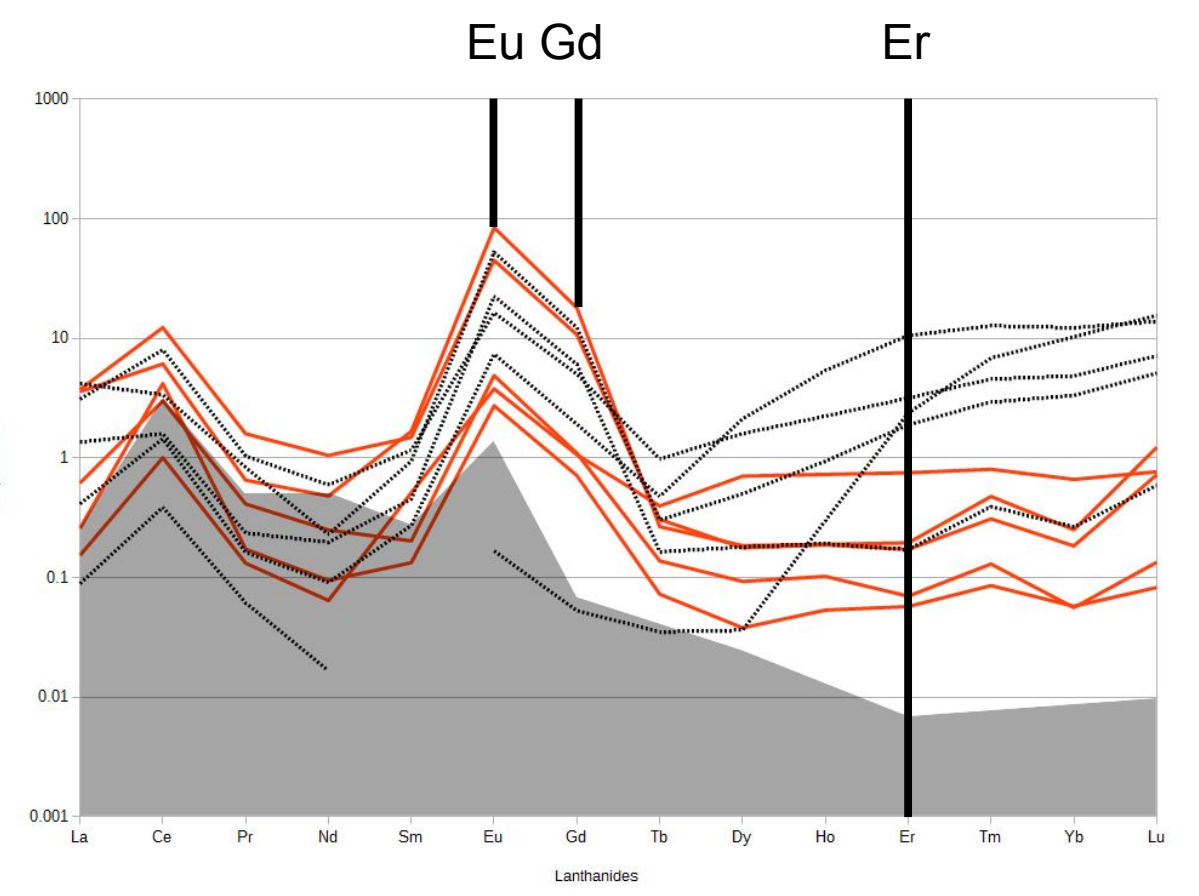

Pine Tree (PRB-18) House Creek (PRB-14) 


\section{Conclusions}

REEs can be measured.

REEs may reflect Geologic Heterogeneity.

Terrestrial/Marine Frac-Sand/Biologics/Age

Many fields have higher concentration than

Ocean Water. This does not necessarily imply a better mine. (oil droplets, TDS, disposal)

Future work will improve our ability to read these signatures and identify what they mean. 


\section{Acknowledgements}

Carbon Management Institute

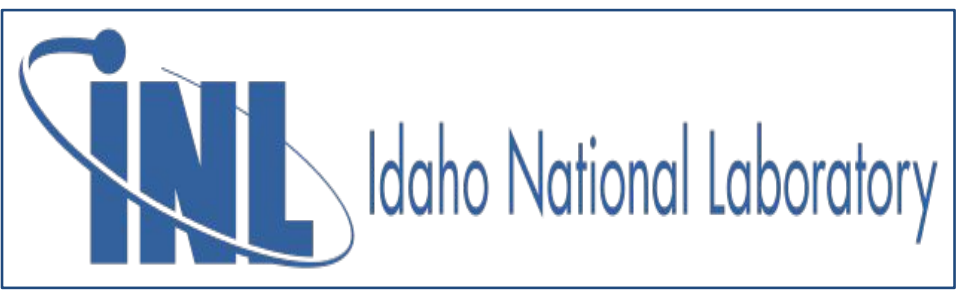

Funding sources:

Team Members:

DOE: EERE

State of Wyoming

University of Wyoming

USGS
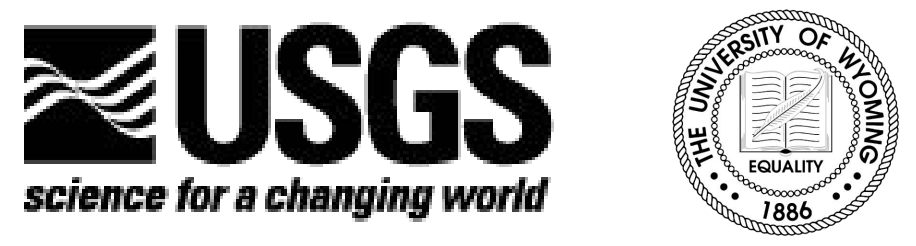


\section{Guidance? Questions? Comments?}

This REE project is just beginning.

We need more data. Collection continues.

We welcome any guidance from experts in the audience. 


\section{Ref}

McLennan, S. M. (2001), Relationships between the trace element composition of sedimentary rocks and upper continental crust, Geochem. Geophys. Geosyst., 2, 1021, doi:10.1029/2000GC000109.

Clark, lan, and Peter Fritz, 1997, Environmental isotopes in hydrogeology: Boca Raton, Fla., Lewis Publishers.

Hatje, Vanessa, Bruland K., and Flegal A. R.“Increases in Anthropogenic Gadolinium Anomalies and Rare Earth Element Concentrations in San Francisco Bay over a 20 Year Record" Environmental Science \& Technology 201650 (8), 4159-4168 DOI: 10.1021/acs.est.5b04322

http://www.sciencedirect.com/science/article/pii/0016703785900900 


\section{Isotopes from Water-Rock}
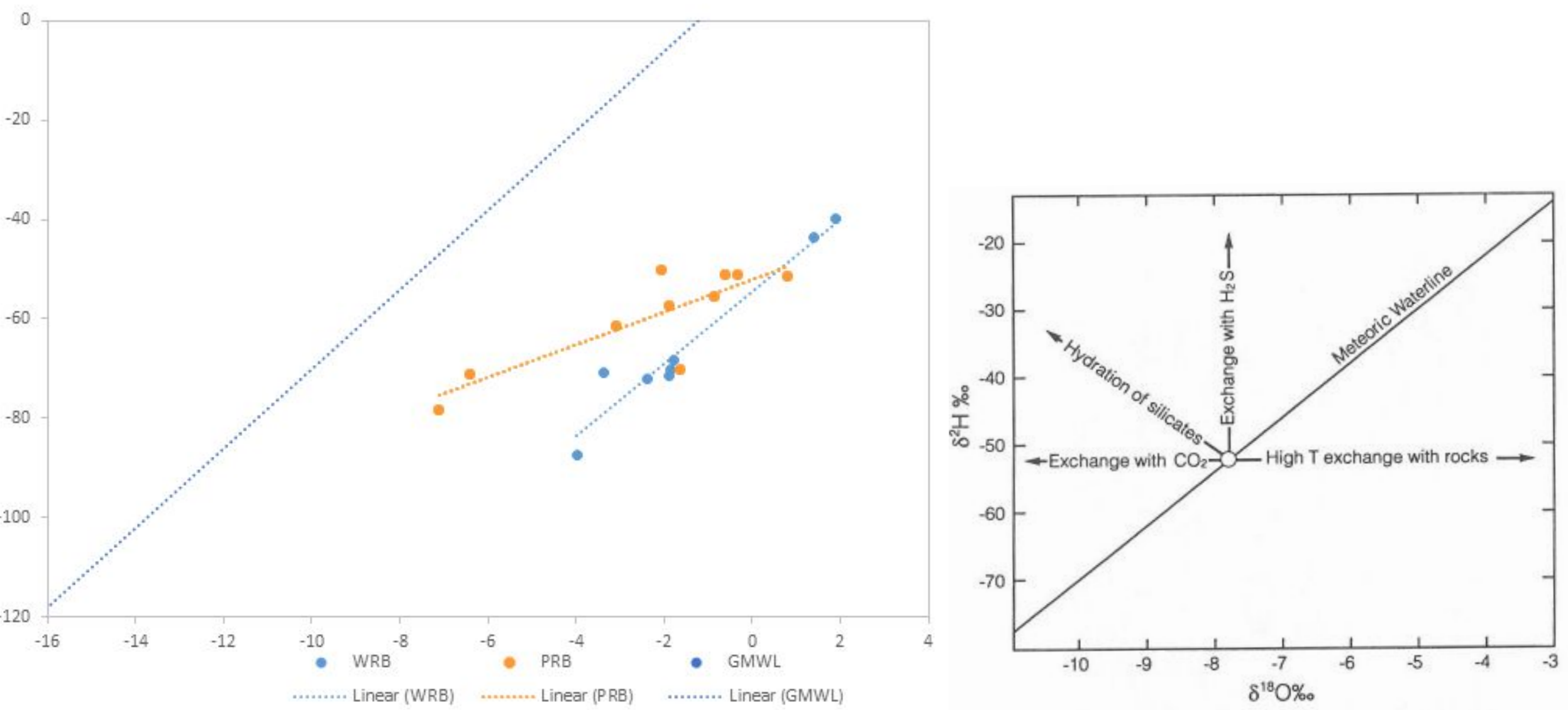

Fig 9-1 Isotope exchange processes that can modify the isotopic composition of meteoric waters.

SCHOOL OF ENERGY RESOURCES 


\section{Isotopes from Water-Rock}

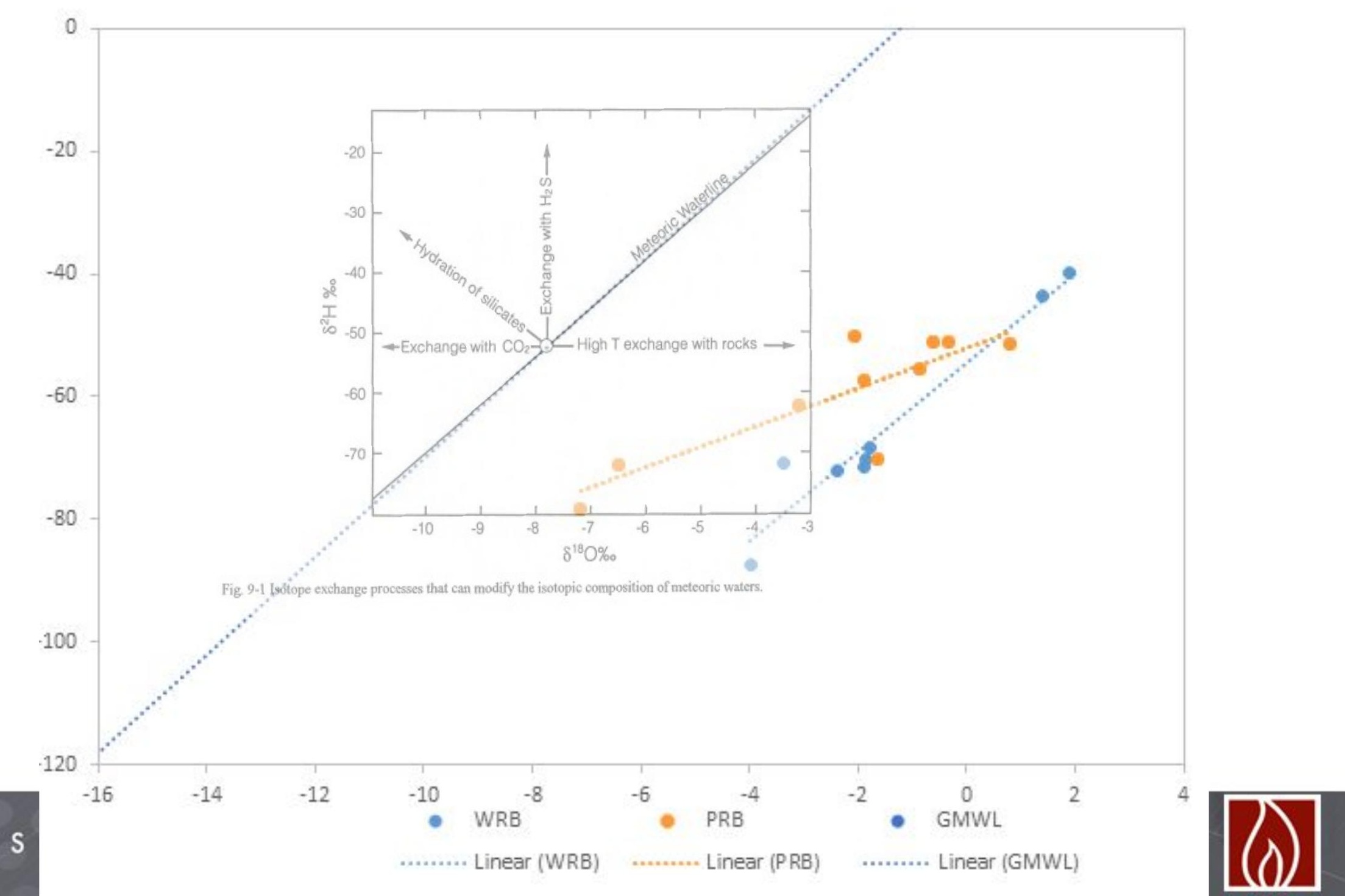




\section{Chondrite ppm and Oddo-Harkins}

Fig from data collected by Korotev 2009

Chondrite REEY

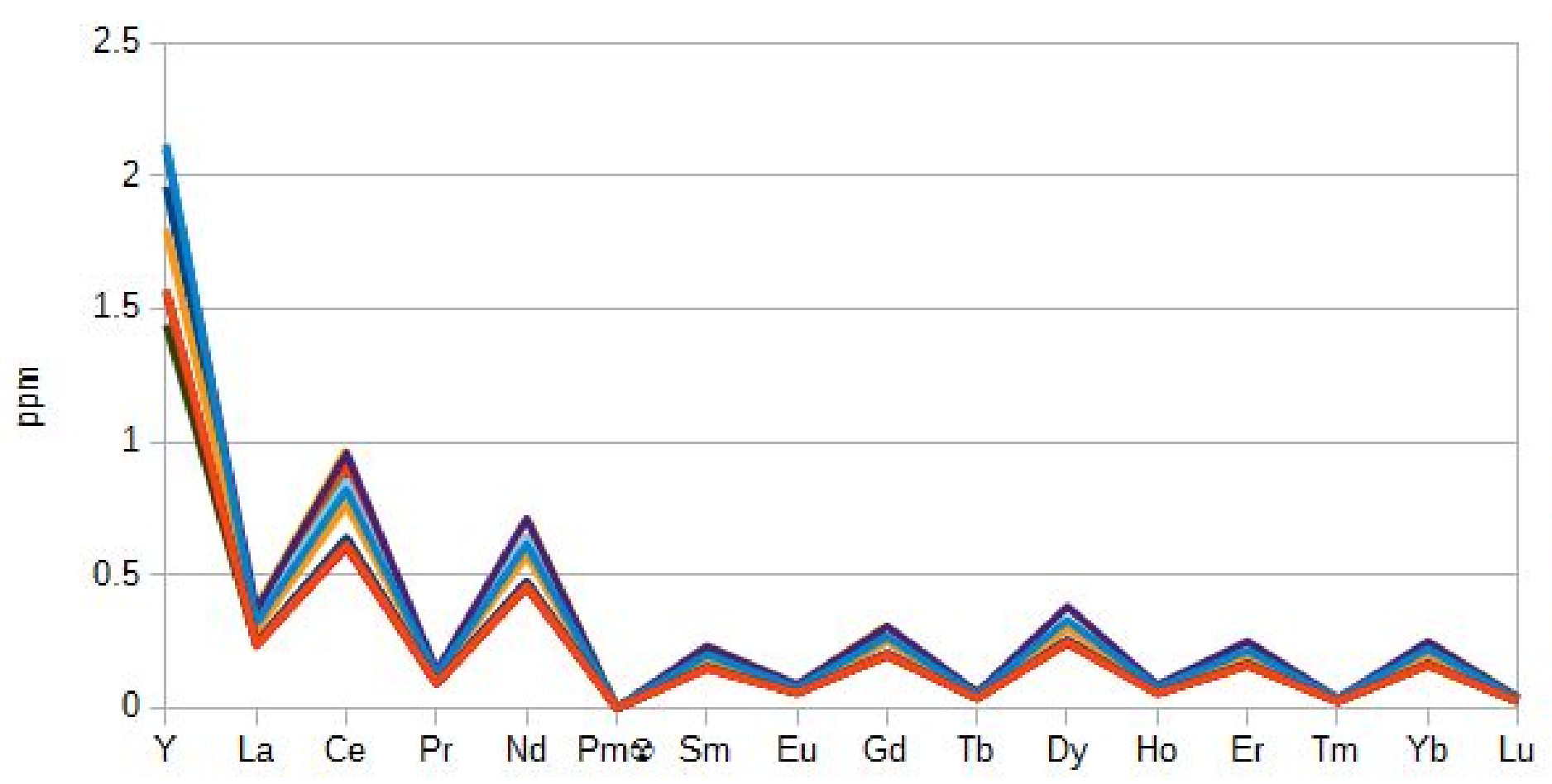

- Hask 68/71 Waki 1971 Masu 1973 Naka 1974 Even 1978 Laul 1979 A\&E 1982 Boyn 1985

- T\&M 1985 W\&K 1988 A\&G 1989 $A \& G \times 1.36$ Palm 1988 M\&S 1995

SCHOOL OF ENERGY RESOURCES 


\section{Gd and MRI}

Gd in near-city waters can indicate Hospitals with MRIs .... but....

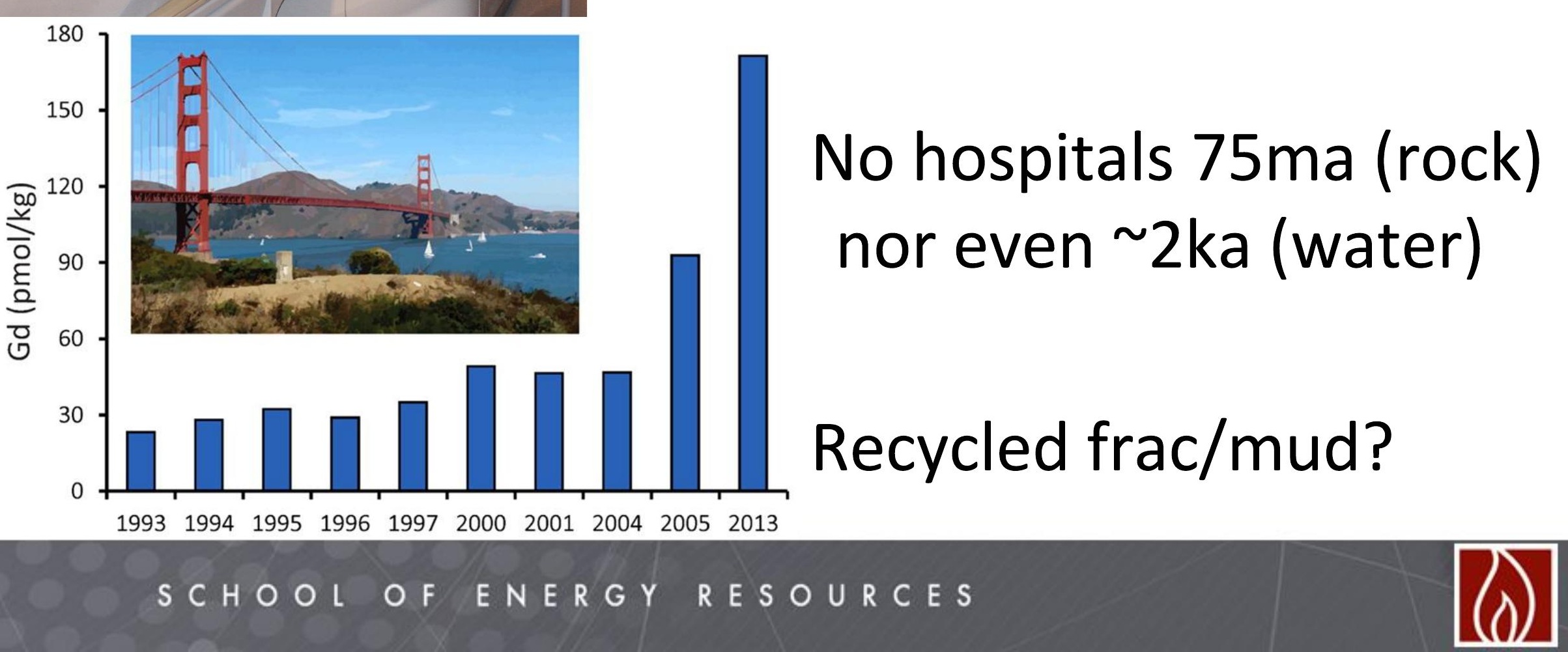

